University of Washington Tacoma

UW Tacoma Digital Commons

Social Work \& Criminal Justice Publications

Social Work \& Criminal Justice

9-2-2015

\title{
Lived Challenges to Ethical Social Work Practice in Criminal Justice Settings
}

Diane S. Young

University of Washington Tacoma, youngd4@uw.edu

Follow this and additional works at: https://digitalcommons.tacoma.uw.edu/socialwork_pub

Part of the Social Work Commons

\section{Recommended Citation}

Young, Diane S., "Lived Challenges to Ethical Social Work Practice in Criminal Justice Settings" (2015). Social Work \& Criminal Justice Publications. 403.

https://digitalcommons.tacoma.uw.edu/socialwork_pub/403

This Article is brought to you for free and open access by the Social Work \& Criminal Justice at UW Tacoma Digital Commons. It has been accepted for inclusion in Social Work \& Criminal Justice Publications by an authorized administrator of UW Tacoma Digital Commons. 
Lived Challenges to Ethical Social Work Practice in Criminal Justice Settings

\author{
Diane S. Young \\ University of Washington at Tacoma
}

\begin{abstract}
Ethical social work practice within criminal justice settings is fraught with challenges. Through individual interviews in a qualitative study exploring social work practice in diverse criminal justice settings in the northwestern United States, a sub-sample of nine social workers described the difficulties they experience adhering to social work's professional code of ethics. They identify two primary areas of divergence, conflicting responsibilities and opposing interests, and identify the ways they respond to these challenges and the rationale behind their decisions. The discussion section explores avenues for strengthening social workers' abilities to be a vital and ethical presence in criminal justice settings.
\end{abstract}


The profession of social work and field of criminal justice currently maintain an uneasy partnership in criminal justice settings where social workers are employed to provide services to client populations. At one time the social work profession was deeply involved in work with criminal justice populations and in criminal justice settings in the United States. For example, social workers were active in the development of the first juvenile court (Gumz, 2004) and were employed in police departments almost a century ago (Van Winkle, 1924). As the profession continued to evolve especially during the last quarter of the $20^{\text {th }}$ century, it moved away from work within criminal justice settings (Gibelman, 1995; Gumz, 2004; Maschi \& Killian, 2011). A 2007 National Association of Social Workers (NASW) membership survey found that only $1 \%$ indicated criminal justice as their primary area of practice (Whitaker \& Arrington, 2008). Mounting concern over high recidivism rates and recognition that psychosocial services are needed to reduce recidivism may create opportunities for social workers to engage more deeply within criminal justice settings once again (Wilson, 2010), although it is too soon to know whether this will come to fruition.

What is at the core of the discomfort between social work and criminal justice? Differing values seem significant. A practice example will illustrate this. Jim, a jail corrections counselor, was asked by Hank, a just-released inmate, for help to get home. Home was several miles away, in a rural area with no public transportation in the evening, and Hank had no one to call for a ride. Local social service agencies were closed for the day and the jail had no fund to assist with transportation. Neither counselor nor released inmate had money for cab fare. Hank was not allowed to stay in the jail lobby until morning when a local social service agency could be contacted for assistance. Jim knew Hank because he had worked with him during his jail stay and offered to give Hank a ride home. This was against jail policy, and the next morning Jim 
was suspended for doing so. Jim firmly believed that his primary responsibility was to his client, Hank. The jail firmly countered that Jim's primary responsibility was to the employing organization and its policies and this superseded the needs of the inmate-client. This is a true story, although the names of both counselor and client are changed in the illustration. In the end, the counseling staff created a petty cash fund to assist others in similar circumstances and the suspended counselor was restored to duty. Before the matter was resolved however, Jim's job was in serious jeopardy and his fellow counselors were left wondering what their own response would have been under similar circumstances. Different perceptions about where the social worker's primary allegiance lies contribute to this clash in values.

The predominant correctional philosophy of retribution, so evident in American systems of criminal justice, is also in direct contrast to social work values regarding the dignity and worth of all. There are correctional philosophies that are more in line with social work values, such as rehabilitation and restoration, but these philosophies currently have, at best, only minor roles in most American criminal justice settings. During the 1970s and after the release of Robert Martinson's (1974) influential work that suggested that rehabilitation efforts did not reduce recidivism, correctional policies were implemented in juvenile justice, community corrections, and adult prisons that were increasingly punitive (Cullen \& Jonson, 2011). This "mean season" in corrections lasted over three decades and brought with it mass incarceration, mandatory minimums, the war on drugs, collateral consequences for released offenders, and an increasing number of juveniles tried as adults (Cullen \& Gilbert, 2013, p. 183). Rehabilitation was largely set aside as a correctional philosophy, and retribution, deterrence, and incapacitation became predominant. With increasing recognition by scholars, politicians, and the public that mass incarceration is not fiscally sustainable and does not reduce recidivism, it is possible that another 
shift in correctional philosophy is beginning. Cullen and Jonson (2011) provide a

comprehensive review of the body of work related to effective correctional treatment and the evidence-based practices that reduce recidivism. The findings are much more promising than they were 40 years ago. In addition, it appears that strong public support for rehabilitation as a correctional priority exists (Cullen \& Gilbert, 2013; Cullen, Skovron, Scott, \& Burton, 1990). In the meantime, the predominant correctional philosophy of retribution continues to shape the work experiences of social workers in criminal justice settings.

The NASW Code of Ethics sets forward standards and principles to guide social workers' behavior, but the implementation of these is not straight forward (NASW, 2008). Seeking "to enhance clients' capacity and opportunity to change and to address their own needs" (NASW, pp. 5-6) is a significant challenge in punitive environments that disregard individual needs. The barriers to practicing social work in ways that affirm the dignity and worth of all people and demonstrate the importance of human relationships by engaging "people as partners in the helping process" (NASW, p. 6) contribute to conflict between the social work and criminal justice professions and create challenges for social workers who practice within criminal justice settings. The NASW Code of Ethics has evolved over time to become quite detailed and comprehensive (see Reamer, 1998, for a history of its development through the 1996 ratification) and yet, by its own admission, is not able to "resolve all ethical issues or disputes or capture the richness and complexity involved in striving to make responsible choices" (p. 4). This is particularly true when the ethical dilemma is one where there are "reasonable arguments for and against different courses of action" (Reamer, p. 495).

It is not only American criminal justice settings where these tensions occur. Fenton (2012) and Gregory (2010) describe the shift in the United Kingdom over the past three decades 
to an approach to offender treatment that is more punitive than in the past. The focus has changed from considering the contexts of offenders' lives and helping offenders through rehabilitation to a much narrower focus on risk management (Fenton, 2012). Criminal justice social workers and other helping professionals have had to move away from time spent on building relationships with individual clients and shared problem solving as part of a behavioral change process to standardized assessment that targets offenders for particular programs (Gregory, 2010). Gregory studied 15 seasoned probation officers, trained from a social work base, to see how they adapted to this change. The probation officers struggled to balance the demands of the strict new approach with the principles they believe important to effective practice: development of relationship and consideration of the complex realities of clients' lives. Similar to the NASW Code of Ethics, the British Association of Social Workers (BASW) Code of Ethics includes principles that require promoting "the full involvement and participation of people using their services" and being "concerned with the whole person...seek[ing] to recognize all aspects of a person's life" (The Policy, Ethics and Human Rights Committee, 2012, p. 8). Fenton (2012), based on a review of research and literature primarily outside of criminal justice, concludes that social workers experience ethical stress when they cannot practice in line with their values.

Other scholars have focused on practice with nonvoluntary and legally mandated clients and the ethical conflicts this work entails with a goal of assisting practitioners in these challenging roles (Burman, 2004; Butters \& Vaughan-Eden, 2011; Rooney, 2009). Rooney notes the highly involuntary nature of institutionalized clients, underscoring that the level of nonvoluntariness typically increases as the perceived loss of freedoms increases. Because of this, extra effort must be made to work with the client to identify and work toward self-defined 
goals. Burman focuses on the dual roles of helper and social control with substance abusing clients, many of whom are in prison or court-referred and mandated clients. Burman suggests expanding the NASW Code of Ethics to include a section on social control and working with mandated clients, especially in relation to informed consent and confidentiality. Butters and Vaughan-Eden provide a revised Code of Ethics for members of the National Organization of Forensic Social Workers (NOFSW). They also give several examples of ethical dilemmas faced within forensic social work including those related to dual roles of helper and social control. As with the NASW Code of Ethics, the NOFSW Code of Ethics cannot resolve all ethical dilemmas, particularly when ethical principles conflict and there are good arguments for diverse actions. For social workers practicing within criminal justice settings, appropriately applying professional ethical principles can be challenging.

\section{Method}

The findings discussed in this article emerged from interviews originally conducted for a qualitative study seeking to understand and describe effective social work practice within criminal justice settings from the perspectives of seventeen social workers doing the work (see Authors' own, 2014). Participants were asked questions such as how they define success in their work, what attributes are needed to be effective and what hinders effectiveness. They were encouraged to provide examples and speak from their experiences. Although direct questions about the role of ethics were not asked, 9 of the 17 participants discussed the importance of ethical practice, ethical conflicts they experienced, and their struggles applying the NASW Code of Ethics within their criminal justice settings. Their expressed internal distress related to ethical social work practice within criminal justice suggests ongoing questions about how the profession 
of social work can meaningfully impact the field of criminal justice. This unanticipated theme of ethical practice, as expressed by the 9 participants, is the focus of this article.

\section{Sampling Procedure and Sample Characteristics}

The original sample of 17 social workers is from a wide range of criminal justice settings from primarily the northwestern United States. Snowball sampling was used to identify individuals with an undergraduate or graduate degree in social work, currently employed to work in a criminal justice setting, and doing work that is considered social work, even if the job title is not "social worker." In many justice settings, social workers work under other titles, such as psychology associate or victim advocate, and this was true for the participants in this study as well. The study was approved by the Human Subjects Division of the author's university and all participants provided written consent. No compensation was provided to participants.

Table 1 provides information comparing the original sample of 17 with the sub-sample of 9 who spoke about ethical practice. Four broad areas of practice are represented in the subsample with only public defense not included. Juvenile rehabilitation includes locked settings as well as community settings. Although there are significant differences between these varied criminal justice settings in scope of responsibility, client population, and specific purpose, it seemed worthwhile in the original study to examine whether the experience of providing social work within them might have common features applicable to criminal justice social workers regardless of setting. One setting that is visibly absent is law enforcement. In the area of the country where the study was conducted, social workers working directly with law enforcement agencies were not found either through direct queries to law enforcement personnel or via suggestions from the participants in the snowball sample. It is interesting to note that very few participants in the full sample could think of more than a few other social workers doing the 
same kind of work at their facility, and in some cases, the entire region or state. This speaks to the relative isolation of forensic social workers in many criminal justice settings.

Overall, there are not many differences between the composition of the original sample and the sub-sample of social workers who spoke about ethical practice. The sub-sample is a less experienced group of social workers when compared to the larger sample (see Table 1);

however, no one had fewer than two years of social work experience in criminal justice. Most of the male participants and those working as administrators or supervisors are included in the subsample, having raised the issue of ethical practice during their interviews.

\section{Study Design and Data Analysis}

All interviews were conducted by the author. The interviews were semi-structured, consisting of pre-developed, open-ended questions, but allowing room for modification and exploration of related topics. The 9 interviews included in the sub-sample ranged from 47-110 minutes, with a mean of 67 minutes. Data collection was concluded when the leads provided by interviewees for prospective participants tapered off significantly. In addition, several recurring themes suggested that saturation was achieved.

Qualitative analysis is especially helpful when the perspectives of participants as insiders are sought on a topic and it is important to understand the contexts that shape those perspectives (Padgett, 2008). The focus of the original study, understanding the complexities of providing effective social work within criminal justice settings, would not easily be captured through quantitative measurement. Interviews were taped and transcribed for analysis, with the exception of two interviews conducted with prison social workers on site. Security personnel did not allow the tape recorder, so extensive notes were taken during the interviews. To verify the accuracy of the notes, the author shared them with each social worker, asking them to make 
corrections or additions. Neither social worker made changes to his/her interview notes. One of these spoke about ethical practice and is included in the sub-sample.

Using an analysis process described by Tutty, Rothery, and Grinnell (1996), the unit of analysis is the "idea." Coding categories were not determined a priori and applied to the text; rather they were gleaned from the text in relation to general open-ended questions about the participants' perceptions of successful social work practice in their work settings, in keeping with the original study's primary research questions (see Authors' own, 2014). The transcripts in their entirety were reviewed for emerging themes. This resulted in a rich array of responses including those centered on ethical practice. To examine this unanticipated theme within the data, all 17 transcripts were then carefully reviewed for any mention of ethics or experiences that described ethical concerns or conflicts. These excerpts, found in 9 of the 17 transcripts, were then studied in a comparative process looking for the expression of common themes in relation to ethical practice and for similarities and dissimilarities across experiences and contexts. The excerpts were then placed into conceptual groupings according to the themes and sub-themes that emerged during analysis. All results were analyzed manually.

All interviews were completed prior to formal analysis. Though this might be considered a drawback in qualitative analysis, it does mean that the findings presented, specifically the frequency with which participants raised certain ideas, is likely due more to their own thoughts and beliefs rather than to the author's probing. Throughout the interview process, a concerted effort was made to explore exceptions and variations of experiences, in part by trying to ensure that the original sample consisted of social workers practicing within different fields of practice within criminal justice.

\section{Findings}


The ethical challenges the nine participants described primarily resulted from the conflicting demands and needs of the employing organization and the individual client and each one's opposing interests. In order to maintain a vital presence within criminal justice settings, the social workers needed to manage these conflicts on a relatively continuous basis. Not to do so in their perspective leads to ineffectiveness or burnout within the rigid criminal justice settings within which they work. Successful prioritization of conflicting responsibilities and compromise and strategic advocacy in response to opposing interests strengthen their ability to remain in the system and continue important programs. Excerpts from the interviews are presented in participants' own words as examples and illustrations of the conflicts they experienced and the compromises they made within the workplace.

The ethical dilemmas the social workers describe occur within the context of rigid and unyielding organizational systems. All criminal justice settings represented by the subsample, regardless of specific type, operate with numerous strict rules, clear chain of command, limited worker autonomy, and serious consequences for violating organizational mandates. Control is exerted over employees as well as those accused of criminal acts, and all are expected to conform to organizational rules. The social workers included here, regardless of specific work setting, provided many examples of rigidity within their environments. One principal consequence of these rigid and unyielding environments is the harsh way that individual clients, e.g., prisoners, delinquents, defendants, and even victims, are perceived and treated. It is this systemic response to individuals that is the backdrop and driver for many of the ethical challenges participants describe, and thus it is important to understand the environmental context. One participant summed up this harsh context well when he said, "actual in-themoment injustices are at their most concentrated in the justice system in terms of how people are 
treating other people and getting away with it." Another, commenting on the rigid nature of criminal justice systems and the social worker's responsibility within it stated, "it's really easy to slip into here is the good guy, here is the bad guy. As a social worker I think part of the goal... is to not fall into that trap." She described the importance of rejecting the rigid thinking that permeates the criminal justice system, where individuals are divided into good guys and bad guys. There was recognition by all participants that the criminal justice systems within which they work are imperfect. They were keenly and sometimes painfully aware of this, and that perception is also part of the backdrop for the ethical dilemmas they experienced.

\section{Conflicting Responsibilities}

The principal area of conflict expressed by participants results from having responsibility to multiple parties and the interests they represent. The organization sees itself as the social worker's primary responsibility, whether it is a juvenile justice setting, prosecutor's office, treatment court, or adult prison. The social worker is thus expected to conduct work in a way that always supports the organizational goals and requirements. From the criminal justice system's perspective, the social worker's priority must be in concert with the organization's interests. Within criminal justice settings and from an organizational perspective, what is important to the individual prisoner, delinquent, defendant, or victim-client is secondary, and more often totally disregarded if it does not line up with organizational values. An overarching stated organizational goal within criminal justice settings is maintaining public safety. This stated goal provides the organizational justification for placing the individual client's needs secondary to those of the system. One participant expressed it this way:

You have to remember that your role is the social worker within the criminal justice setting and so you have to be cognizant that treatment is not first, that safety comes first 
and that...my client is not my client. My client is the court. The court is my client and if I forget that and I treat the participant as my client, then I'm doing something wrong because the court's client is the community and so that's where safety comes in first. And so before my client's needs, I have to look at the court's needs and the need to protect community safety before I get to my client. So the participant who would be the typical social worker's client is farther down the list.

Social workers described experiencing ethical dilemmas when the organization's expectations and the needs of the individual client conflict. These dilemmas take different forms, and the personal anxiety caused by each dilemma is shaped by what is perceived to be at stake, personally and for the client. One prison social worker described an "ugly ethics dispute" when he was ordered to give up the name of a client who had disclosed to the social worker in a counseling session that harm would come to another prisoner if the prisoner was returned to the same housing unit. There was no clear agency rule that required the social worker to give up the name of the informant, and in the past, confidential reports had sufficed. This time a supervisor ordered the release of the name. Typically, the administration would accept the report, do its own information gathering, and then make a decision about prisoner housing placement. This way, individual prisoner safety is enhanced without jeopardizing the confidential nature of the therapist-client relationship. This dispute went on for some time while the social worker sought advice from professional colleagues, mental health services administration, and internal investigations. In the end, the order stood requiring the release of the name, and the social worker informed the client and then provided the name to a mental health supervisor. This dispute took a heavy emotional toll on the social worker. He described his struggle to continue 
to practice to the best of his ability, which he viewed as an ethical responsibility, during this time.

The big thing is you hold onto social work standards and ethics and practice and fight - I mean, internally, fight every step of the way to keep clients first. And to just do everything so that your own stuff doesn't harm treatment. And to just do whatever you can to put the crap aside so that you're present. And that's an internal battle.

This ethical conflict was perhaps the most personally painful one described by a participant, but others also expressed conflicts resulting from having multiple responsibilities as the following examples demonstrate.

One social worker in the juvenile justice system talked about "not wanting to be the man." Yet in juvenile parole revocation hearings, one of the possible outcomes is returning the client to the institution. She stated,

I see it as a tool in the toolbox we have. But at the same time, it's still sending a kid back to an institution....I understand it, and I see that it might help or work. And it might - it will protect the community. It will protect them from themselves in some cases. But at the same time, it's a hard one.

She is describing a struggle between following organizational expectations and the client's wishes, with client or public safety as the stated backdrop. Another social worker, working within a treatment court and seeking to reduce obstacles to client success in the community, described how she was ordered to remove from her reports the statement that local law enforcement encourages people not to rent to felons. This practice creates barriers for her individual clients who need housing, but the organizational entities she works with put requirements on what she can include in her report out of concern for organizational 
relationships. Balancing the demands of multiple partiess requires the social worker to prioritize among them each time these kinds of conflicts occur, creating ethical dilemmas for the social worker to resolve.

\section{Managing Opposing Interests}

Against the backdrop of pressures from multiple responsibilities, the nine social workers struggled to maintain a vital presence in the system and to act in ways congruent with social work values. This struggle, expressed numerous times by participants, is about walking a fine line between advocating for the individual client and fitting in well enough with the system so that one is allowed to continue in the system. Managing the demands of conflicting interests was often done through compromise between what the social worker ideally wanted to do and what the system was perceived to tolerate. One prison social worker described this at the level of selfpreservation. "The social worker walks a fine line because your job is to advocate for the offender in need. You were hired to help someone in need....But your own self-preservation kicks in - you have a mortgage." In contrast to this, most participants expressed the cost of these conflicts not as self-preservation but as the ability to be heard and accepted, effective in work, and able to continue valued social work programs within criminal justice settings in order to achieve a greater good.

To be heard and accepted requires, in the views of these participants, the ability to ascertain when to advocate for an individual client and when to refrain from doing so. One social worker working within a treatment court stated, when you're "always advocating for someone...you won't be taken seriously and you won't be given credibility by the prosecutors and by the corrections staff." Credibility is critical to having influence within the organization, and without influence, advocacy has little return because no one is listening. To gain credibility, 
the social worker must be accepted by the host organization and the majority within it who are not social workers. A victim advocate stated, "the way you survive is by creating alliances with the people that you're working with every day, and the people you're working with every day don't have the same viewpoint that you do." She made this statement in the context of describing the struggle she experiences when the prosecutor wants to do something that she believes is not in the best interest of a victim and yet, she must maintain an ongoing working relationship with the prosecutor. She explained that victim-clients are not always benefitted by the plea bargaining negotiations that prosecution and defense use to settle most cases, and victim advocates must determine when to vigorously pursue individual client advocacy and when to back down in order to preserve future voice within the system.

Compromise in the face of opposing interests also entails tolerating views and behaviors you do not support in order to be effective in your daily tasks and win the larger battle of continuing treatment programs. One prison social worker described the personal struggle of getting along with prison officers that act in direct contrast to the social work values he holds regarding the dignity and worth of each person.

I see the guards just behaving really shabbily toward the inmates on a regular basis. Rude, disrespectful, taunting. Certainly not all of them, certainly not all the time. Some of the officers there are very, very talented, compassionate, insightful people that are just a big help. But nevertheless, I see some really childish behavior. But I have to get along with those officers because they sort of see me as one of them because I'm staff. I also need them to like me because they can also mess with me, too. If you don't have the cooperation of the officers, your inmates may not show up for their appointments....All kinds of things could happen. 
To accomplish the daily social work tasks, cooperation from the host organization is essential. Though expressed most poignantly by this participant, others also shared their internal turmoil and great effort to work well with other criminal justice professionals who hold beliefs about individuals in direct opposition to their own. This was viewed as a necessity, not only for maintaining ongoing daily tasks but also for the longevity of treatment programs provided within host organizations. One social worker who is a prison administrator talked about the imperative for social workers within criminal justice systems to choose their battles in order to be successful in the end. She describes the social worker who would not be effective inside the criminal justice setting.

Getting angry or frustrated at an ongoing set of behavior when you know the larger battle is continuing the programs....It's asking an advocate not to be an advocate in every situation. It's asking someone who is used to advocating for programs...to step back and choose your battles.... Someone who gets too angry at social injustices... and can’t contain that to fight for the larger picture.

From the perspectives of the participants in this sample, for social workers to persevere and programs to continue, compromise and strategic advocacy are required. Compromises are made, but not easily and not without personal and professional struggle around what ethical practice requires.

As participants described the ethical dilemmas they faced, they also touched on strategies or mindsets they employ to help them persevere within criminal justice host settings. Two of these approaches, rejecting dichotomous thinking that classifies individuals as good or bad and using an ethical framework for decision making, must be implemented even while other employees around you do not necessarily adhere to the same practices. According to the 
perspectives of these participants, to avoid burnout and persevere, it is essential to believe that one is a part of solving the problems within the system even while working in it.

\section{Discussion}

Working within rigid criminal justice systems, nine social workers described the ethical challenges they face as they strive to be effective in juvenile rehabilitation, adult prison, treatment court, and victim advocacy. They described conflicts related to multiple responsibilities and markedly different interests and their reasons for compromising to address opposing interests. All have wrestled with the conflicts. Although a small sample, their examples resonate with the experiences of other social workers in criminal justice settings in the United States (Butters \& Vaughan-Eden, 2011), Canada (Crawford, 1999), and the United Kingdom (Fenton, 2012; Gregory, 2010).

A struggle throughout the social work profession's history has been that of challenging the status quo or supporting it (Abramovitz, 1998). Park (2008) writes a compelling and detailed narrative about social workers' active involvement in Japanese internment camps in the United States during World War II. She writes that our profession "facilitated unjust government policies" and acted on social biases, while at the same time trying to mitigate the consequences of the policies (p. 474). Rooney (2009), writing about work with institutionalized and involuntary clients, comments that many of us are better at influencing personal change than structural change, but if we do not try to change structures, we are at risk of engaging in social control while smiling. Alexander (2012) in the New Jim Crow outlines numerous criminal justice policies and practices that continue to perpetuate racial discrimination in profound ways. One is left wondering whether unjust practices within our criminal justice systems might end more quickly if all our advocacy efforts were targeted toward systemic changes brought about by 
pressure from outside these systems. The decision to work from within the system is in itself an ethical dilemma the social workers grappled with. After all, it is not possible for social workers to maintain their positions as employees within criminal justice organizations if they vigorously advocate against its policies and practices. As demonstrated in these participants' experiences, compromises are required in order to maintain within the system.

The criminal justice social workers in this sample sought to mitigate the effects of harsh criminal justice policies and practices while working from within the system. Criminal justice systems, regardless of specific setting, act in ways that are unresponsive to individual human needs. Social workers in this sample described their efforts to effectively meet individual client needs within these restrictive environments. This work is critically important if the underlying assumption, best expressed by Lowe and Bohon (2008), is accurate, that social workers will not have much of an "impact on inhumane or unresponsive" systems if we only practice in places that line up with social work values (p. 300). Numerous individuals are caught up within and affected by criminal justice systems. Choosing not to respond to their immediate needs when we have skills to offer because of discomfort or even blatant disagreement with the system does not seem defensible. Thus, a critical question remains. If social workers want to impact these systems from the inside, how do we strengthen our ability to be a vital and ethical presence in this setting?

The social workers in this sample struggled with the application of ethical social work practice. After all, regarding the system's goals as most important is quite different from much of social work practice education and training where primacy is placed on promoting the wellbeing and interests of individual clients. At times, the social workers chose to behave in ways that were dissonant to their understanding of the NASW Code of Ethics in order to achieve other 
goals such as establishing credibility, being accepted as part of the team, and supporting organizational authority. These compromises were made for the practical purpose of maintaining presence in the setting. In addition, they were made to enhance one's ability to be a vital and effective presence within the limitations of the setting. The challenge for these social workers was not to discontinue advocacy but to astutely determine when and how to advocate.

The social work professional Code of Ethics provides guidance for practice within criminal justice settings, but cannot resolve all dilemmas (NASW, 2008). This is true for practice settings outside of criminal justice as well, but it would benefit criminal justice social workers if the profession recognized that criminal justice settings may demand unique application of social work values. This is not a new idea, having been suggested by Severson (1994) in relation to confidentiality and informed consent and Burman (2004) in relation to the dual roles of helper and social control with mandated, substance-abusing clients. The struggle to determine what ethical practice requires should not be left to the individual practitioner alone. Ongoing collegial systems of support, put into place to assist criminal justice social workers experiencing ethical dilemmas, would serve the dual purposes of reducing the professional isolation often experienced in this work and adding greater expertise to problem solving discussions. Perhaps established professional organizations such as the Council on Social Work Education, the National Association of Social Workers, and the National Organization of Forensic Social Workers, which has had a Code of Ethics for its members since 1987 (Butters \& Vaughan-Eden, 2011), could be possible leaders in the development of these collegial networks. Expanding this network to include international colleagues managing similar ethical challenges would further enrich the discussion. 
The findings reported here do not result from a purposeful exploration of the ethical dilemmas social workers in criminal justice settings experience. Rather, they were an unexpected theme emerging from a study focused on effective social work practice within criminal justice. The findings should be viewed as preliminary and verified through future research, in part because of the small sample size. The sample also does not represent all types of criminal justice settings, and it is possible that if questions had been directly asked about ethical practice to the larger sample, a greater range of experiences would have been reported. The sub-sample overall includes a less experienced group of social workers. Perhaps less experienced criminal justice social workers wrestle more with ethical dilemmas, and with greater time in the field they learn how to better respond to these challenges personally and professionally. This explanation does not seem wholly satisfactory however, as six of the nine participants in the sub-sample have more than five years' experience in criminal justice settings. Future research should purposefully explore and also compare the perspectives on and experiences with ethical practice between less experienced and more seasoned social workers within a larger group of social workers in a variety of criminal justice settings and geographic locations. A larger descriptive study would help clarify the extent to which ethical dilemmas are experienced by social workers in these settings and, if present, provide a more complete picture of the nature of the dilemmas.

One area of research that stands to significantly benefit criminal justice social work practice has to do with making clear the causal relationships between criminal justice responses to individual clients, whether offenders, delinquents, defendants, or victims, and public safety. The prevailing organizational view is that public safety is best ensured when the criminal justice organization's goals and requirements are supported. Thus, if the organization's practices are 
punitive and rigid, as is the predominant American approach, this is purported to be what is best for public safety. But what if this is not accurate? What if the current organizational practices do not in fact promote public safety, but rather hinder it, especially in the long term? In addition, punitive collateral consequences for former offenders, such as statutory and regulatory restrictions related to employment, public assistance, and public housing, undermine individuals' efforts to successfully integrate into families and communities after incarceration (Burton, Fisher, Jonson, \& Cullen, 2014). Recidivism rates in the United States remain extremely high, in spite of the large number of individuals placed under social control (Durose et al., 2014). A comparison of criminal justice policies between Nordic Countries and the United States suggest the effectiveness of alternative approaches without jeopardizing public safety. The countries of Norway, Finland, Sweden, and Denmark have strikingly low incarceration rates and reduced public fear of crime together with practices such as the greater use of community service and electronic monitoring as true alternatives to incarceration (Lappi-Seppälä, 2012). Mediation, a restorative justice practice, is institutionalized by national law in all four countries (LappiSeppälä, 2012), a stark contrast to correctional policy in the U.S. There is also a growing body of evidence that indicates the types of correctional treatment that enhance public safety through reduced recidivism, largely originating from the work of Canadian scholars (Cullen \& Jonson, 2011). Research that continues to clarify the factors that reduce criminal recidivism and help victims, families, and offenders achieve restoration and well-being would promote understanding about what public safety truly requires.

In the meantime, the environmental contexts of criminal justice settings will not change quickly, and social workers seeking to maintain a vital presence within will find themselves sometimes at odds with the behaviors and views of the employing organization. To prevail and 
be perceived as valuable contributing partners by the organization, suggestions from the literature on working within host organizations are helpful. Host organizations are described as organizations "whose mission and decision making are defined and dominated by people who are not social workers" (Dane \& Simon, 1991, p. 208), clearly the case for social workers working within criminal justice settings. Some of these strategies include: aligning your mission with that of the host organization's in some way, helping with logistical or practical problems the setting faces, demonstrating that social work services help reduce problems the host organization wants to avoid, and finding pockets of support within the organization (Dane \& Simon, 1991; Janssen \& Simmons, 1986). The ability to employ these strategies and the specific nature of what that might look like will vary depending on the specific criminal justice setting. Nevertheless, finding ways to demonstrate value to the organization by means that do not conflict with social work values will benefit social worker, individual client, and the criminal justice host organization. In the end, social workers will need to be "diplomatic and assertive" when faced with challenges that conflict with professional values (Dane \& Simon, p. 209), a statement the social workers in this sample found true to their experience.

Crawford (1999), an educator and social worker conducting group therapy with assaultive men in a Canadian prison, wrote that he was advised to work with those "about whom others feel most hopeless" (p. 208). That those involved with criminal justice systems are individuals "about whom others feel most hopeless" is a sentiment that many criminal justice social workers would likely agree. Vigorous advocacy to change harmful criminal justice policies and practices are needed and are a responsibility of the social work profession. Much of the work that is needed is perhaps best done from the outside through political and legal action. At the same time, maintaining a vital presence inside criminal justice settings is important and also a 
Running head: CHALLENGES TO ETHICAL PRACTICE 23

responsibility of the social work profession. Finding ways to strengthen the ability of social workers on the inside to practice ethically and effectively fits well with our professional mission. 


\section{References}

Authors' own, 2014.

Abramovitz, M. (1998). Social Work and social reform: An arena of struggle. Social Work, 43(6), 512-526.

Alexander, M. (2012). The new Jim Crow: Mass incarceration in the age of colorblindness. New York, NY: The New Press.

Burman, S. (2004). Revisiting the agent of social control role: Implications for substance abuse treatment. Journal of Social Work Practice, 18(2), 197-210.

Burton Jr., V.S., Fisher, C.M., Jonson, C. L., \& Cullen, F.T. (2014). Confronting the collateral consequences of a criminal conviction: A special challenge for social work with offenders. Journal of Forensic Social Work, 4(2), 80-103.Butters, R.P., \&VaughanEden, V. (2011). The ethics of practicing forensic social work. Journal of Forensic Social Work, 1(1), 61-72.

Crawford, M. (1999). A hard day's night: Working with assaultive men in prison. In L.M. Grobman (Ed.), Days in the lives of social workers (pp. 205-209). Harrisburg, PA: White Hat Communications.

Cullen, F.T. \& Gilbert, K.E. (2013). Reaffirming rehabilitation. Boston: Elsevier. Cullen, F.T., \& Jonson, C.L. (2011). Rehabilitation and treatment programs. In J.Q. Wilson \& J. Petersilia (Eds.), Crime and public policy (pp. 293-344). New York: Oxford University Press.

Cullen, F.T., Skovron, S.E., Scott, J.E., \& Burton Jr., V.S. (1990). Public support for correctional treatment. Criminal Justice and Behavior, 17(1), 6-18. 
Dane, B.O., \& Simon, B.L. (1991). Resident guests: Social workers in host settings. Social Work, 36(3), 208-213.

Durose, M.R., Cooper, A.D., \& Snyder, H.N. (2014, April). Recidivism of prisoners released in 30 states in 2005: Patterns from 2005 to 2010 (NCJ 244205). Washington, DC: Office of Justice Programs.

Fenton, J. (2012). Bringing together messages from the literature on Criminal Justice Social Work and 'disjuncture': The importance of 'helping.' British Journal of Social Work, $42,941-956$.

Gibelman, M. (1995). What social workers do. Washington, DC: NASW.

Gregory, M. (2010). Reflection and resistance: Probation practice and the ethic of care. British Journal of Social Work, 40, 2274-2290.

Gumz, E.J. (2004). American Social Work, Corrections and restorative justice: An appraisal. International Journal of Offender Therapy and Comparative Criminology, 48(4), 449460.

Jansson, B.S., \& Simmons, J. (1986). The survival of social work units in host organizations. Social Work, 31(5), pp. 339-343.

Lappi-Seppälä, T. (2012). Penal policies in the Nordic Countries 1960-2010. Journal of Scandinavian Studies in Criminology and Crime Prevention, 13(Supp 1), 85-111.Lowe, L.A., \& Bohon, S.A. (2008). Specialized social work education: The case for social work with offenders. Families in Society: The Journal of Contemporary Social Services, 89(2), 293-301.

Martinson, R. (1974). What works? - questions and answers about prison reform. The Public Interest, 35(Spring), 22-54. 
Maschi, T., \& Killian, M.L. (2011). The evolution of forensic social work in the United States: Implications for $21^{\text {st }}$ century practice. Journal of Forensic Social Work, 1(1), 8-36.

National Association of Social Workers. (2008). Code of Ethics. Washington DC: NASW.

Padgett, D.K. (2008). Qualitative methods in social work research. Thousand Oaks, CA: Sage.

Park, Y. (2008, September). Facilitating injustice: Tracing the role of social workers in the World War II internment of Japanese Americans. Social Service Review, 447-483.

Reamer, F.G. (1998). The evolution of social work ethics. Social Work, 43(6), 488-500.

Rooney, R. (2009). Strategies for work with involuntary clients. New York: Columbia Press.

Severson, M.M. (1994). Adapting Social Work values to the Corrections environment. Social Work, 39(4), 451-456.

The Policy, Ethics and Human Rights Committee. (2012, January). The code of ethics for social work: Statement of principles. Birmingham, England: British Association of Social Workers.

Tutty, L.M., Rothery, M.A., \& Grinnell, R.M. Jr. (1996). Qualitative research for social workers: Phases, steps, \& tasks. Boston: Allyn and Bacon.

Van Winkle, M. (1924). The policewomen. Proceedings of the fifty-first annual session of the National Conference of Social Work. Chicago: University of Chicago Press.

Whitaker, T., \& Arrington, P. (2008). Social workers at work. National Association of Social Workers Membership Workforce Study. Washington, DC: National Association of Social Workers.

Wilson, M. (2010). Criminal justice social work in the United States: Adapting to new challenges. Washington, D.C.: NASW Center for Workforce Studies. 
Table 1. Sample Characteristics Comparison

\begin{tabular}{|c|c|c|}
\hline Characteristic & $\begin{array}{l}\text { Interviewees }(\mathrm{N}=17) \\
\text { Original Sample }\end{array}$ & $\begin{array}{l}\text { Interviewees }(\mathrm{N}=9) \\
\text { Sub-sample on } \\
\text { Ethical Practice }\end{array}$ \\
\hline \multicolumn{3}{|c|}{ Field of Practice in Criminal Justice } \\
\hline Adult prison & 6 & 3 \\
\hline Juvenile rehabilitation & 4 & 2 \\
\hline Treatment court & 4 & 2 \\
\hline Prosecution & 2 & 2 \\
\hline Public defense & 1 & 0 \\
\hline \multicolumn{3}{|l|}{ Level of Responsibility } \\
\hline Administrator/Supervisor & 5 & 4 \\
\hline Line Level Practitioner & 11 & 4 \\
\hline Both & 1 & 1 \\
\hline \multicolumn{3}{|c|}{ Experience in Criminal Justice } \\
\hline $1-5$ years & 4 & 3 \\
\hline $6-10$ years & 5 & 4 \\
\hline $11-15$ years & 3 & 1 \\
\hline More than 15 years & 5 & 1 \\
\hline \multicolumn{3}{|l|}{ Social Work Degrees $^{\mathrm{a}}$} \\
\hline Bachelors & 4 & 1 \\
\hline MSW & 17 & 9 \\
\hline Ph.D. & 1 & 1 \\
\hline \multicolumn{3}{|l|}{ Gender } \\
\hline Female & 12 & 5 \\
\hline Male & 5 & 4 \\
\hline \multicolumn{3}{|l|}{ Race } \\
\hline Caucasian & 14 & 8 \\
\hline African American & 2 & 1 \\
\hline Unknown & 1 & 0 \\
\hline
\end{tabular}

${ }^{a}$ Totals are greater than sample sizes because some participants had more than one social work degree. 